\title{
The Bus Arrival Information System for Tunanetra Based on Firebase Cloud Messaging and Google Text to Speech
}

\author{
G Aryotejo ${ }^{1 *}$, Ahmad Syarifuddin Hidayatulloh ${ }^{2 * *}$, Mufadhol Mufadhol ${ }^{3 * *}$ \\ * Information System of Sekolah Tinggi Elektronika dan Komputer, Majapahit 561, 50192, Semarang, Indonesia \\ ** Computer System of Sekolah Tinggi Elektronika dan Komputer, Majapahit 561, 50192, Semarang, Indonesia \\ guruh2000@yahoo.com ${ }^{1}$, ahmad.syarifuddin.hidayatulloh@gmail.com ${ }^{2}$, masyong29@gmail.com ${ }^{3}$
}

\begin{tabular}{l}
\hline \hline Article Info \\
\hline Article history: \\
Received 2020-06-10 \\
Revised 2020-12-14 \\
Accepted 2020-12-15 \\
\hline
\end{tabular}

Keyword:

Public Transportation System, Blind people, Bus Information System, Arduino, Raspberry Pi

\begin{abstract}
Buses are one of the means of public transportation and there are also services provided by the Government to the community and their construction must meet standards so that the community can use them. Bus-type public transportation in the city of Semarang only stops at every bus stop. The current problem is that bus stops in the city of Semarang are not friendly to people with disabilities, especially for blind people. They have to wait for the bus to arrive then ask people around the identity of the bus that is coming. This study aims to build a bus arrival information system using a combination of Arduino Uno, Raspberry Pi 3B, LCD, nRF24L01 module, LED, Speaker, Google Text to Speech and Firebase Cloud Messaging. We perform the simulation by analyzing the transceiver connectivity on the bus to the information system transceiver and providing the obstacles in between. In addition, we also tested the maximum distance of the transceiver device on the bus stop connected to the router. Furthermore, the information systems usage time at bus stops using various power banks was also tested. We found that the transceiver on the bus and the information system transceiver was connected to a maximum distance of 40 meters and was not affected by rainy weather. In addition, the system execution time is highly dependent on the internet connection used on the information system transceiver. Meanwhile, the maximum distance between the information system and the router is also very dependent on the transceiver capability of the router and the information system. Furthermore, the time to use the information system using the Power Bank indicates that the greater the power bank, the longer the information system will be used. This shows that this system is suitable for use by the blind in using public transportation and becomes the basis for research in helping the blind.
\end{abstract}

This is an open access article under the $\mathrm{CC}-\mathrm{BY}-\mathrm{SA}$ license.

\section{INTRODUCTION}

Public transportation is one of the services provided by the Government for the community. Its construction must meet the standards with the aim that all people can use it. Currently, not all people in society can use this public accessibility to its full potential, such as the people with disabilities.

Persons with disabilities are someone who has physical or mental limitations who need help with facilities and infrastructure, especially in carrying out their activities. Persons with disabilities are one person who can not be separated from the help of others and existing public accessibility. One of the facilities and infrastructures that cannot be utilized and used maximally by people with disabilities is accessibility at Trans Semarang bus stops and buses.

Public transportation such as buses are currently still widely used to travel to various places because they are safe, cheap and comfortable. Bus-type public transportation in the city of Semarang only stops at every bus stop. Bus passengers must first come to the nearest bus stop in order to use Semarang city buses. The current problem is that bus stops in the city of Semarang are not friendly to people with disabilities, especially for blind people. Blind people do not know the arrival and bus information. They have to wait for

http://jurnal.polibatam.ac.id/index.php/JAIC 
the bus to arrive then ask people around the identity of the bus that is coming.

The voice-assisted bus stop system can provide information on the identity and arrival time of buses that can be understood by the visually impaired. This system is equipped with the nRF24L01 Wireles RF Module (Send) sensor which is connected via the Arduino Uno R3. The device will provide real-time bus identification and arrival time information. When the bus distance has reached a predetermined limit, the receiving device at the stop consisting of the nRF24L01 Wireles RF Module (Recive) and Raspberry Pi will provide information in the form of voice generated by Google Text to Speech. The resulting information is in the form of bus identity and preparation for passengers. This research is expected to be useful for a blind person to find out the identity and arrival information of the bus without having to ask the people around him.

\section{THEORETICAL BASIS}

\section{A. Understanding Information Systems}

Information system is a network of interrelated procedures, gathered together to obtain data that is processed into a form that is more useful and more meaningful for those who receive it, while the data is a source of information that describes a real event. [1]

\section{B. Firebase Cloud Messsaging}

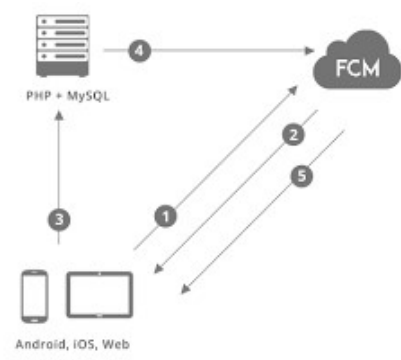

Figure 1: Firebase Cloud Messaging

Firebase Cloud Messaging (FCM) is a cross platform messaging solution that allows users to send notifications reliably at no cost. [2] Furthermore, FCM has the ability to give commands to applications on the smartphone to do certain things by simply sending notification data [3]

\section{C.Text to Speech}

Google Text to Speech is an application in the field of language technology, which can convert text in the format of a language into speech in accordance with the reading of the text in the language used, by performing phonetization, namely the preparation of phonemes to form speech [4][5].

\section{RESEARCH METHOD}

Development model is needed as a basis for product development that refers to the Research and Development
(R\&D) model of Borg and Gall. The R\&D model is a design model of design development that aims to develop and validate products. The selection of the Borg and Gall model is based on consideration of development models that are already structured and programmed with careful preparation and planning steps. The steps taken in this research use the $\mathrm{R}$ \& D development model approach which only adopts 6 (six) stages out of 10 (ten) R\&D (Bor and Gall) stages as follows: (a) research and information gathering, (b) planning, (c) roduct development (system design), (d) initial field tests (design validation), (e) major product revisions (design revisions), (f) advanced field tests (field trials). [6]

The product to be created will then be used for testing prototype products by users. The tests are: (1) The physical appearance of the prototype product, (2) The nRF24L01 module works normally, (3) Does it improve using an automatic system more than manual information, (4) The feature of providing information through voice on the speakers in Bus Stop.

\section{A. Current System}

The flowchart of the results of conducting research into the Bus Arrival Information System for the Blind is as follows:

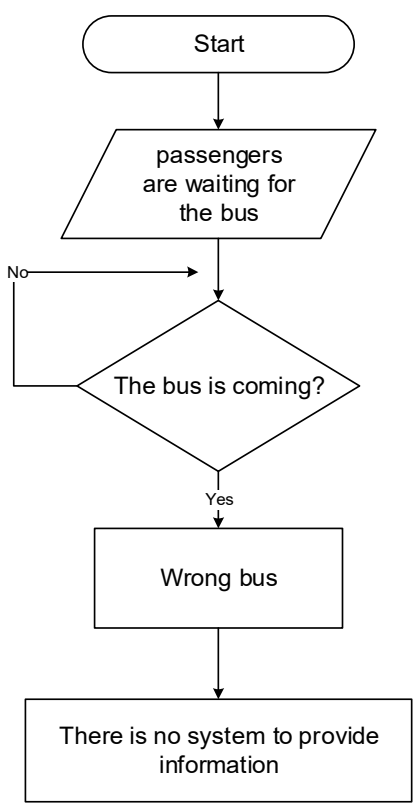

Figure 2: Old Bus Arrival System Flowchart

The old system at the arrival of the Trans Semarang Bus is that the bus arrives without information in the form of votes for people with disabilities where the bus only comes accidentally.

\section{B. Proposed System}

Based on research, the resulting system is shown below. 


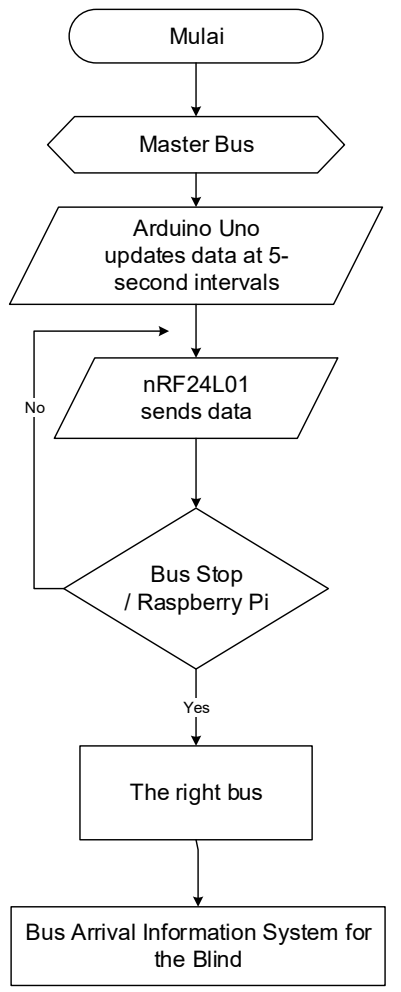

Figure 3: Proposed Bus Arrival System Flowchart

The new system design that we designed was to utilize the Arduino Uno R3 microcontroller on the bus and Raspberry Pi, then the speaker will automatically sound when the existing system on the bus is approaching the bus stop. [7]

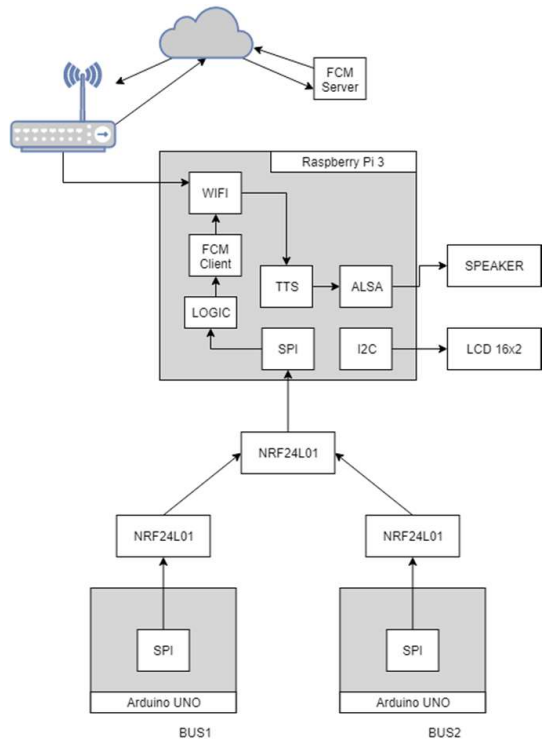

Figure 4: System Block Diagram
The diagram above explains how the system works in outline. Each bus has a transmitter device consisting of Arduino UNO and NRF24L01 modules. This NRF24L01 module sends a signal with the format "BUS01" where index 01 matches the corridor number of each bus. When the transmission distance is equal to or less than the distance to the stop that has a receiving device, then the signal from the bus will be received by Raspberry Pi through NRF24L01. The result will activate Text To Speech with an argument in the form of a bus number. Raspberries also send push notification requests to Firebase Cloud Messaging when a bus approaches. A $16 \times 2$ LCD is also used by Raspberry pi to display bus information that is approaching. NRF24L01 uses the SPI (Serial Peripheral Interface) protocol for dealing with Arduino and Raspberry Pi . While the LCD uses the I2C (Inter Integrated Circuit) protocol, and the speaker uses the ALSA (Advanced Linux Sound Architecture) protocol. Data from the FCM Client and TTS is sent to the internet via the WiFi module that is on the Raspberry Pi.

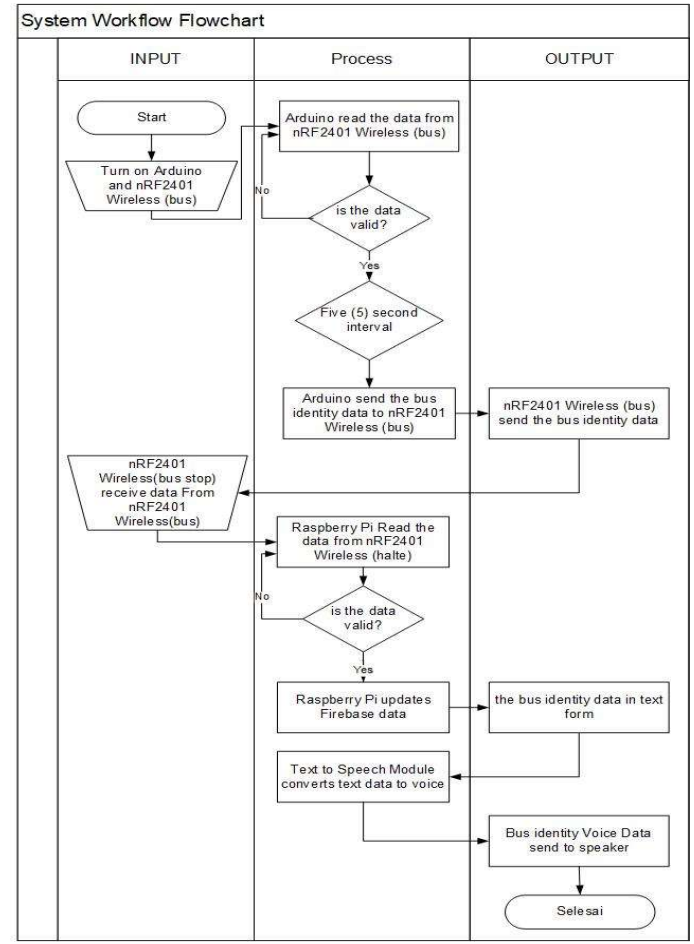

Figure 5: System Workflow Chart

Flowchart in Figure 5 describes how the system works. The nRF24L01 module will look for a signal, if a signal is caught, the signal will be processed through Arduino Uno [8]. Arduino will send bus identity data via a signal which will then be received by the information system at the stop consisting of a Raspberry pi and speakers. The information system will verify the signal and update the data from Firebase. Furthermore, the data will be converted into voice 
with the Text to Speech module, which results in a notification in the form of a bus identity.

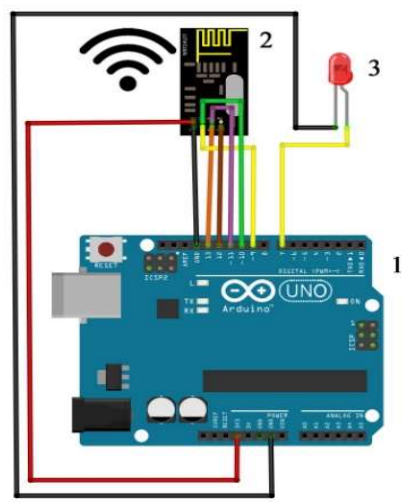

Figure 7: Schematic design of the transceiver device on the bus

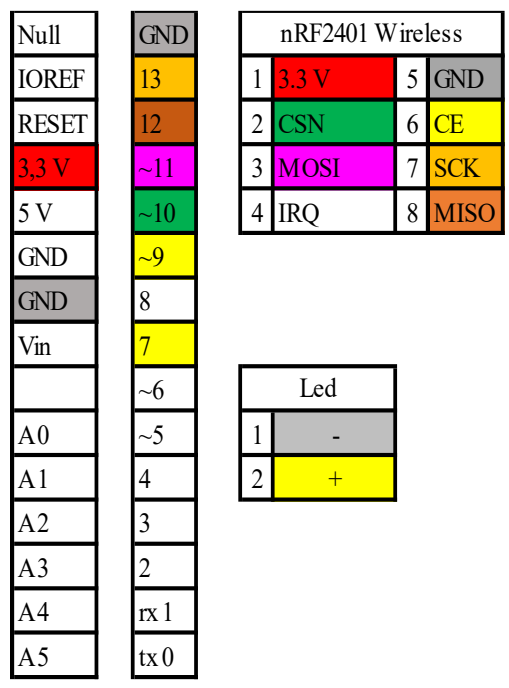

Figure 8: Arduino Uno R3 pinout on transmitter

The circuit scheme of transceiver device on the bus require several components such as Arduino uno R3, nRF24L01 and led as seen in figure 5 and table $1 . n R F 24 L 01$ is a wireless module act as as a transceiver and use a $3.3 \mathrm{~V}$ voltages depicted on figure 6 . The input and output in this sequence are controlled by the Arduino Uno R3.

\section{TABLE 1.}

SYSTEM COMPONENT OF TRANSCEIVER DEVICE ON THE BUS

\begin{tabular}{|c|l|}
\hline No & \multicolumn{1}{|c|}{ Components } \\
\hline 1 & Arduino Uno R3 \\
\hline 2 & nRF24L01 Modul \\
\hline 3 & Led \\
\hline
\end{tabular}

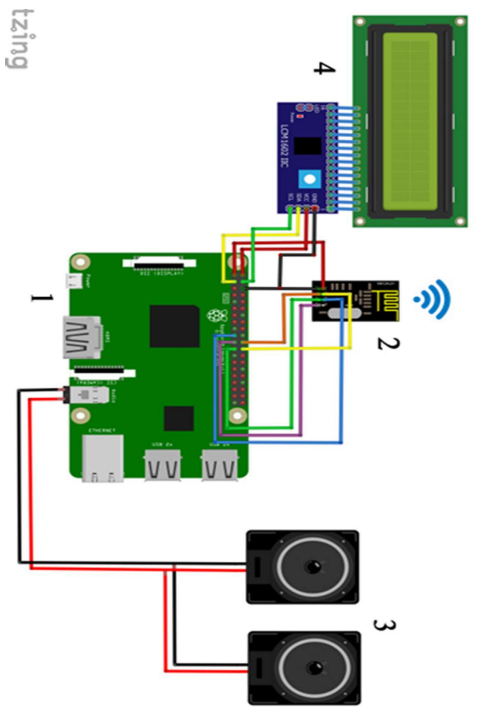

Figure 6: Information System Device Circuit Schematic

The transceiver on the bus stop requires several components such as Raspberry Pi, nRF24L01 Wireless, LCD and speakers as depicted on figure 7 and table 2. This component power source requires multiple power supplies from $5 \mathrm{~V}$ to $12 \mathrm{~V}$ [9], [10]. The input and output in this series are controlled by the Raspberry Pi as seen on figure 8 .

\begin{tabular}{|r|l|l|l|}
\hline 3,3 V PWR & 1 & 2 & 5 V POWER \\
\hline GPIO 2 & 3 & 4 & 5 V POWER \\
\hline GPIO 3 & 5 & 6 & GND \\
\hline GPIO 4 & 7 & 8 & GPIO 14 \\
\hline GND & 9 & 10 & GPIO 15 \\
\hline GPIO 17 & 11 & 12 & GPIO 18 \\
\hline GPIO 27 & 13 & 14 & GND \\
\hline GPIO 22 & 15 & 16 & GPIO 23 \\
\hline 3,3 V PWR & 17 & 18 & GPIO 23 \\
\hline GPIO 10 & 19 & 20 & GND \\
\hline GPIO 9 & 21 & 22 & GPIO 25 \\
\hline GPIO 11 & 23 & 24 & GPIO 08 \\
\hline GND & 25 & 26 & GPIO 07 \\
\hline ID_SD & 27 & 28 & ID_SC \\
\hline GPIO 5 & 29 & 30 & GND \\
\hline GPIO 6 & 31 & 32 & GPIO 12 \\
\hline GPIO 13 & 33 & 34 & GND \\
\hline GPIO 19 & 35 & 36 & GPIO 16 \\
\hline GPIO & 37 & 38 & GPIO 20 \\
\hline GND & 39 & 40 & GPIO 21 \\
\hline
\end{tabular}

\begin{tabular}{|l|l|}
\hline \multicolumn{2}{|c|}{ Lcd $4 \times 4$} \\
\hline 1 & SCL \\
\hline 2 & SDA \\
\hline 3 & VCC \\
\hline 4 & GND \\
\hline
\end{tabular}

\begin{tabular}{|l|l|l|l|}
\hline \multicolumn{3}{|c|}{ nRF2401 Wireless } \\
\hline 1 & $3.3 \mathrm{~V}$ & 5 & GND \\
\hline 2 & CSN & 6 & CE \\
\hline 3 & MOSI & 7 & SCK \\
\hline 4 & IRQ & 8 & MISO \\
\hline
\end{tabular}

Figure 9: Arduino Uno R3 pinout Information System

TABLE 2.

SYSTEM COMPONENT OF INFORMATION SYSTEM.

\begin{tabular}{|c|c|}
\hline No & Components \\
\hline 1 & Raspberry Pi \\
\hline 2 & nRF24L01 Modul \\
\hline 3 & Speaker \\
\hline
\end{tabular}




\section{RESEARCH AND DISCUSSION}

The first simulation is testing the transceiver device connectivity on the bus. The LED lights up red when nRF24L01 connected to the Information System Devices and was not light up when there is no connection, as seen in Figure 9.

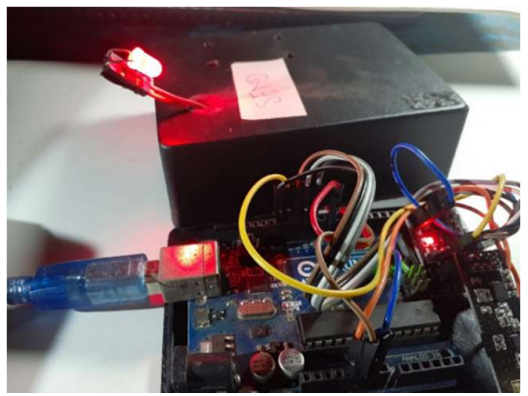

Figure 10: The red LED lights up when nRF24L01 connected to Information System Devices

The second simulation is testing the LCD display on the information system Device. The LCD will display the message "Menunggu Jaringan" (Waiting for Network) when searching for a network, while it will display the message "Tidak ada Jaringan" (no network) when not connected to a network. When connected to the network, the LCD will display the IP Address. The system will display "Akan datang: Bus koridor 1" (Corridor 1 bus has arrived) when connected to transceiver on the corridor one bus and will display "Selamat datang" (Welcome) when the the corridor 1 bus has left the bus stop, as shown in figure 10 .
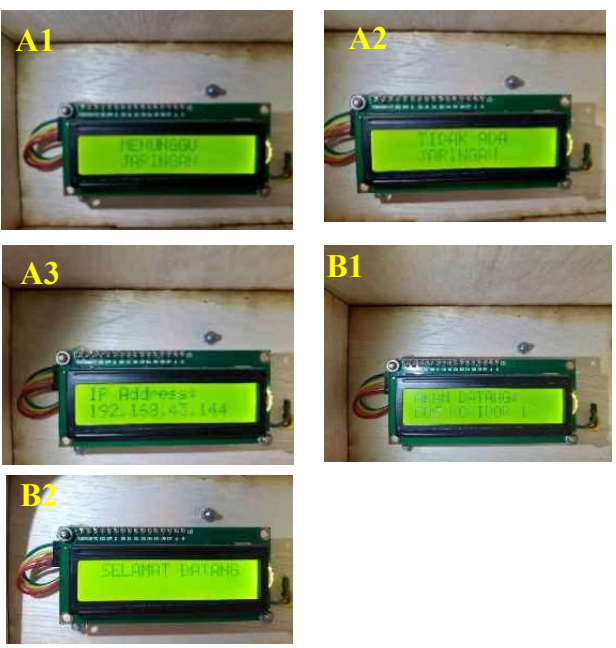

Figure 11: A) The LCD displays on the bus (A1) The message "Menunggu Jaringan" (Waiting for Network); A2) The message "Tidak ada Jaringan" (no network); A3) The message contains IP Address.); B) The $L C D$ displays on information system Device (B1) The message "Akan datang: Bus koridor 1" (Corridor 1 bus has arrived); B2) The message "Selamat datang" (Welcome)).
The third simulation is to analyze the connectivity between the transceiver on the bus and the information system transceiver. The simulation distance was 10 - 100 meters and was given obstacles in the form of trees, walls, rain and without obstacles. The result is depicted on figure 11 .

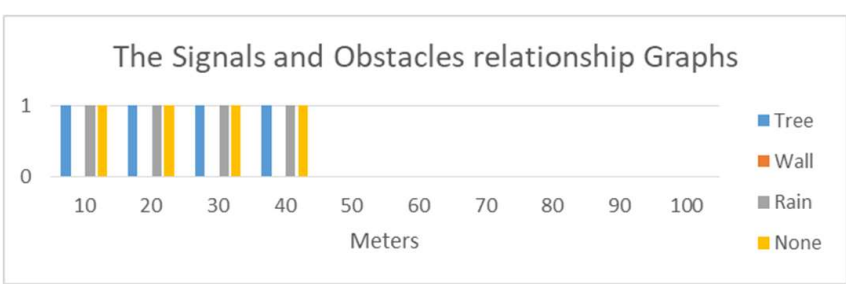

Figure 12: The signals and Obstacles relationship Graphs (Y-axis value: $1=$ connected, $0=$ not connected).

The simulation result shows that radio signals at a distance of 10 to 40 meters were not have a problem, but the signal got interference and the devices was not connected at a distance of 50 to 100 meters.

The fourth simulation is testing the system execution time based on the type of connection by comparing the execution speed on the Indihome and Portable Hotspot (smartphone) as well as in clear and rainy weather, as can be seen on figure 12 .

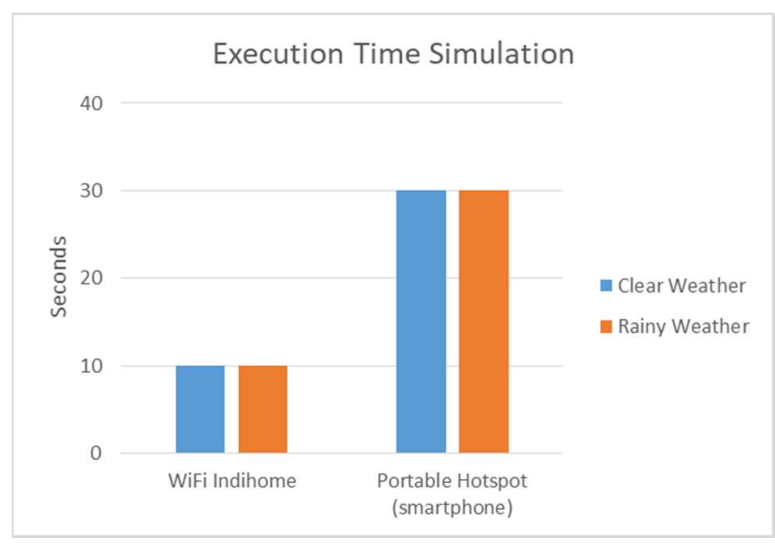

Figure 13: Execution Time Simulation

The simulation result shows that the choice of connection type shows the difference in execution time. This can be seen from the use of Indihome WiFi only takes 10 seconds to execute, while using Portable Hotspot (Smartphone) takes 30 seconds. Furthermore, the weather difference did not make a difference in execution time. The use of WiFi Indihome on sunny time and rainy time both requires execution time of 10 seconds, while using Portable Hotspot (Smartphone) on sunny time and rainy time both require 30 seconds of execution time

The fifth simulation is to test the maximum distance of the information system transceiver on the bus stop connected to the router, as depicted on figure 13 . 


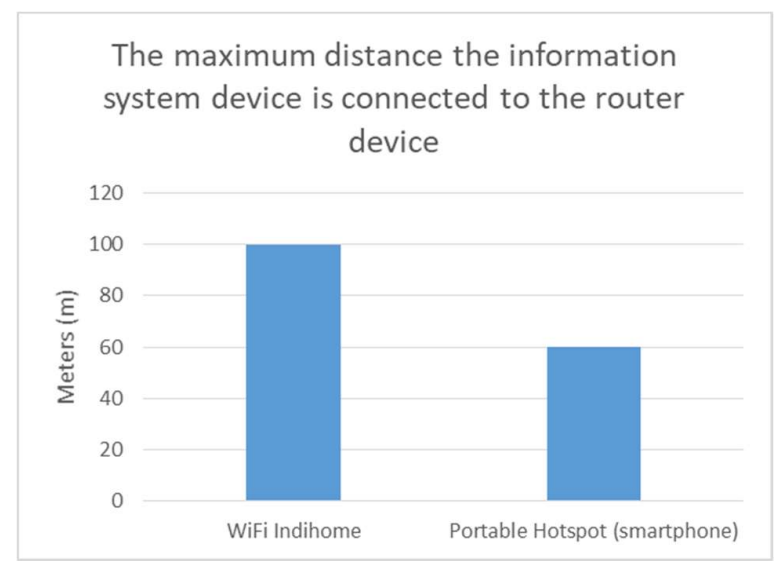

Figure 14: The maximum distance the information system device on the bus stop is connected to the router device.

The result shows that the WiFi Indihome capable of providing distances of up to 100 meters, while the portable hotspot (smartphone) was only able to provide connectivity up to 60 meters.

The last simulation is to test the usage time of the information system device at the bus stop using power banks of various powers, as can be seen on figure 14

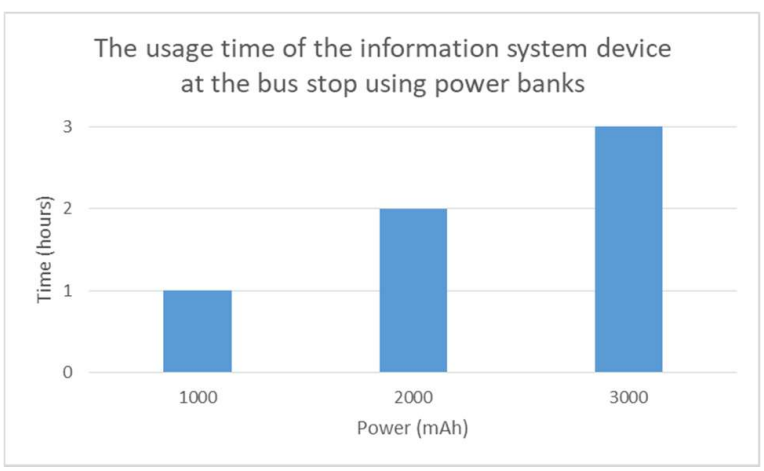

Figure 15: the usage time of the information system device at the bus stop using power banks

The simulation results show that the $1000 \mathrm{mAh}$ power bank is able to provide up to 1 hour of power, while the 2000 and $3000 \mathrm{mAh}$ provide power for up to 2 and 3 hours, respectively.

\section{CONCLUSION}

From the analysis and discussion that has been done, based on several tests conducted, it can be concluded that this system can help the blind in using public transportation. This can be seen by providing information in the form of LEDs and voice notifications at bus stops. The simulation results show that this system can function normally in sunny and rainy weather up to 40 meters. In addition, using a good internet network can also increase the response time by up to 10 seconds. The maximum distance for an information system device to connect to the router is 100 meters using WiFi Indihome. Furthermore, the information system device can operate for up to 4 hours using a $3000 \mathrm{mAh}$ power bank. This shows that this system is suitable for use by the blind in using public transportation and becomes the basis for research in helping the blind.

\section{DAFTAR PUSTAKA}

[1] A. Mulyanto, Sistem Informasi Konsep dan Aplikasi. Yogyakarta: Pustaka Pelajar, 2009.

[2] Fadli, "Rancang Bangun Penentu Arah dengan Rambu Pada Koridor Untuk Penyandang Tunanetra dengan Output Suara Berbasis Raspberry Pi, Jurnal Online Teknik Elektro," Univ. syiah kuala, vol. 2, 2017, [Online]. Available: 2252-7036.

[3] M. A. Mokar, S. O. Fageeri, and S. E. Fattoh, "Using firebase cloud messaging to control mobile applications," Proc. Int Conf. Comput. Control. Electr. Electron. Eng. 2019, ICCCEEE 2019, pp. 2-6, 2019, doi 10.1109/ICCCEEE46830.2019.9071008.

[4] A. Arry Akhmad, "An Introduction to Text to Speech," teknologibahasa, 2008. .

[5] B. IANCU, "Evaluating Google Speech-to-Text API's Performance for Romanian e-Learning Resources," Inform. Econ., vol. 23, no. 1/2019, pp. 17-25, 2019, doi 10.12948/issn14531305/23.1.2019.02.

[6] M. D. Gall, J. P. Gall, and W. R. Borg, Applying Educational Research: How to Read, Do, and Use Research to Solve Problems of Practice (7th Edition). Pearson, London., 2014.

[7] Leo Tiofan Justica, "Rancang Bangun Aplikasi Messaging Berbasis Voice Interaction Bagi Penderita Tunanetra Pada Sistem Operasi Android, Jurnal Pengembangan Teknologi Informasi dan Ilmu Komputer," Univ. Brawijaya, vol. 1, 2017 , [Online]. Available: 2548-964X.

[8] K. Abdul, Buku Pintar Pemograman Arduino. Yogyakarta: Mediakom, 2015

[9] H. Chaudhari, "Raspberry Pi Technology: A Review," Int. J. Innov. Emerg. Res. Eng., vol. 2, no. 3, pp. 83-87, 2015.

[10] K. Abdul, Buku Dasar Raspberry Pi. Yogyakarta: Andi, 2017. 